\title{
Irrigation frequency and soil type influence germination and early growth of quinoa (Chenopodium
}

\section{quinoa Willd)}

\author{
${ }^{1}$ Paul Chaibva., ${ }^{1}$ Cecil Mugala., ${ }^{1}$ Veronica Makuvaro., ${ }^{1}$ Tavagwisa Muziri., ${ }^{2}$ Ignatius Chagonda., ${ }^{3}$ Blessing \\ Mirika Ndau \\ ${ }^{1}$ Department of Agronomy and Horticulture, Midlands State University, Bag 9055, Senga, Gweru, \\ Zimbabwe \\ ${ }^{2}$ Department of Agricultural Practice, Midlands State University, Bag 9055, Senga, Gweru, Zimbabwe \\ ${ }^{3}$ Department of Land and Water Resources, Midlands State University, Bag 9055, Senga, Gweru, \\ Zimbabwe \\ chaibvap@staff.msu.ac.zw (corresponding author)
}

\begin{abstract}
The adoption of quinoa as a potential food crop in semi-arid Zimbabwe is threatened by poor seed establishment. A 4 x 3 factorial experiment arranged in a completely randomised design (CRD) was carried out to establish the effects of irrigation frequencies and different soil types on germination and early growth of quinoa. Three soil types (sand, loam, and clay) and four irrigation frequencies (after every 1, 2, 3, and 4 days) were used. Measurements taken included days to $50 \%$ emergence, germination percentage, mean germination time, germination rate index, coefficient velocity of germination, seedling height, final crop stand, and root density. Analysis of variance (ANOVA) was done using GenStat $18^{\text {th }}$ Edition and mean separation was done using the Least Significant Difference (LSD) at a 5\% significance level. There was an interaction between irrigation frequency and soil type on days to $50 \%$ emergence $(p<0.05)$, germination percentage $(p<0.05)$, germination rate index $(p<0.05)$, seedling height $(p<0.05)$, root length density $(\mathrm{p}<0.05)$, seedling crop stand $(\mathrm{p}<0.05)$. Sandy soil irrigated on 1-day intervals recorded the highest germination percentage (96.7\%), while clay irrigated on 3-day intervals recorded the lowest (41.7\%) final germination percentage respectively. Seeds planted in sand and clay recorded the shortest (3.25) and longest (4.5) mean germination time (days) respectively. Loamy and sandy soils irrigated on 3-day intervals and 1day intervals recorded the lowest $(29.4 \%)$ and highest $(70.4 \%)$ germination rate index respectively. Loam soil irrigated on 1-day and 4-day intervals recorded the highest $(16.37 \mathrm{~cm})$ and shortest $(9.3 \mathrm{~cm})$ seedling height. Loam soil irrigated on 2-day and sandy soil irrigated on 3-day intervals recorded the lowest $\left(3.07 \mathrm{~cm} / \mathrm{cm}^{3}\right)$ and the highest $\left(21.23 \mathrm{~cm} / \mathrm{cm}^{3}\right)$ root length densities respectively. Sand irrigated on 1-day intervals recorded the highest $(85 \%)$ crop stand. Findings concluded and recommended planting and frequently irrigating quinoa in sandy soils for better crop establishment.
\end{abstract}

Keywords: Quinoa production, water requirement, early crop development, soil type 


\section{INTRODUCTION}

The introduction of domestically grown quinoa (Chenopodium quinoa Willd) in developing countries, especially in Africa, to be part of the diet has great potential in contributing to food and nutrition security [1-3]. As long back as the early 1990s, the potential of quinoa for agro-based African economies was noticed as it was envisaged that the crop could be grown extensively in Africa in response to the growing demands of the crop in Asia, Europe and the USA [4]. Quinoa has attracted special attention around the globe due to its health and nutritional benefits, as well as its amazing ability to adapt to different growing environments, which include but not limited to nutrient-poor, saline soils and drought-prone marginal areas [5-8]. In general, quinoa is regarded as a drought-tolerant crop that can grow successfully and produce seed grain even in the dry semi-desert conditions that receive an annual rainfall of less than $200 \mathrm{~mm}$ [9-12] and even under extremely dry environments $[13,14]$. The crop has been found to thrive in areas susceptible to drought in Africa [7].

The introduction of quinoa in Africa started in the late 1990s in Ethiopia and Kenya [15], Malawi in 2010 [16] and more recently in Zimbabwe in 2017 by the Zimbabwe Resilience Building Fund (ZRBF) [17]. The introduction of quinoa in Zimbabwe is meant to address topical issues on food security, hunger, malnutrition and poverty in the face of the detrimental effects of climate change and variability. In Zimbabwe, there is a decline in the production of staple food crops such as maize and wheat and this is having a negative impact on most smallholder farming communities in terms of food security and nutrition [18]. Food security in Zimbabwe is continuously being threatened by prolonged dry spells and droughts, especially in semi-arid regions, which are the most affected

Quinoa production in the country is still in its infancy [17] and the successful rollout and scaling up to more smallholder farmers in marginal areas is being hampered by poor germination which is subsequently affecting the ultimate crop stand. Although considered a drought-tolerant crop, the germination and emergence percentage reported by many smallholder quinoa farmers during the initial rollout phase in 
Lupane and Zvishavane districts of Zimbabwe are as low as 30\%. These preliminary observations by the authors motivated this research as this is directly affecting yield and potential revenue as well as quinoa adoption by the smallholder farming communities. There is limited research on ways that might improve the germination and emergence of quinoa in low rainfall or marginal areas.

Therefore, the main aim of this study sought to evaluate different water application frequencies on different soil types on early quinoa crop establishment.

\section{MATERIALS AND METHODS}

\subsection{Experimental site}

The experiment was carried out at the Midlands State University (Zimbabwe) campus in a greenhouse with an average temperature of $33^{\circ} \mathrm{C}$. The site is located at $29^{\circ} 84^{\prime} \mathrm{E}, 19^{\circ} 49^{\prime} \mathrm{S}$ and is elevated at $1420 \mathrm{~m}$ above sea level and falls under the Agro-ecological zone (Natural Region) III of Zimbabwe that receives an annual average rainfall range of $600-750 \mathrm{~mm}$ per annum.

\subsection{Experimental design and treatments}

The experiment was set up in a complete randomized design (CRD) and laid out as a $4 \mathrm{x} 3$ factorial treatment structure with two factors; irrigation frequency and soil type. The irrigation regimes were irrigation after every 1 day, 2 days, 3 days and 4 days until the end of the experiment and the soil types were sand, loam and clay. The treatments were replicated three times.

\subsection{Experimental procedure}

Styrofoam seedling trays (200-cell) were filled with the different types of soils (sand, loam and clay), each treatment was made up of 20 cells replicated 3 times, watered to field capacity and left to drain excess water. The different soil types were irrigated after skipping every 1, 2, 3 and 4 days.

\subsection{Soil properties measured}




\subsubsection{Bulk density}

Nine core rings were used to collect soils, three core rings for each soil type. Firstly, the site was cleared off residues and then the core rings were driven into the soil. The core ring was then carefully lifted and excess soil was removed using a serrated knife. The initial weight of the core ring was established and then the soil samples were placed in a drying oven for 24 hours at 105 degrees Celsius. After 24 hours the rings were weighed, had their final weight recorded and then bulk density was calculated using the formula according to Blake [19];

$\mathrm{Db}($ bulk density $)=\frac{\text { Mass of oven }- \text { dry soil }}{\text { Total volume }}$

\subsubsection{Porosity}

Porosity was calculated according to the formula by Hao et al. [20].

St (porosity) $=1-\frac{D b}{D p(2.5)}$

\subsubsection{Soil $p H$}

The $\mathrm{pH}$ was measured using a $\mathrm{pH}$ meter, PH TESTER PH-107. Following the procedure by Rayment and Lyons [21], air-dried samples of the three soils were mixed with a diluted concentration of $0.01 \mathrm{M}$ of calcium chloride $\left(\mathrm{CaCl}_{2}\right)$ in a 1:5 ratio. Twenty (20) grams of each soil was measured, added to a beaker and then $100 \mathrm{ml}$ of the concentration. The beaker was then shaken and left to stand for 20-30 minutes. Thereafter, the $\mathrm{pH}$ meter was dipped in the solution while avoiding contact with soil and readings were collected.

The different soil properties measured are presented in Table 1.

Table 1: Soil bulk density, porosity and $\mathrm{pH}$ results of the soils used in the study.

\begin{tabular}{lccc}
\hline Soil Type & Bulky Density $\left(\mathbf{g} / \mathbf{c m}^{\mathbf{3}}\right)$ & Porosity & $\mathbf{p H}$ \\
Sand & 1.2 & 0.96 & 5.5 \\
Clay & 0.91 & 0.85 & 6.3 \\
Loam & 0.83 & 0.83 & 6.8 \\
\hline
\end{tabular}




\subsection{Quinoa growth parameters measured}

\subsubsection{Days to $50 \%$ emergence}

The days were recorded when $50 \%$ of the seedlings had emerged.

\subsubsection{Final Germination Percentage}

It was measured up to the point when no more seeds were germinating.

It was calculated as germination $\%=\frac{\text { number of seeds germinated }}{\text { total number of seeds sown }} \times 100 \%$

\subsubsection{Mean Germination Time (MGT)}

The mean germination time (MGT) was established using the equation by Ellis and Roberts [22]:

$\mathrm{MGT}=\frac{\sum D n}{\sum n}$

Where $n$ is the number of seeds that germinated on day $\mathrm{D}$ and $\mathrm{D}$ is the number of days counted from the beginning of germination.

2.5.4 Coefficient Velocity of Germination $(C V G)$

CVG indicates rapidity of germination,

$\mathrm{CVG}=\frac{N 1+N 2+N 3 \ldots . . N x}{100(N 1 T 1+N 2 T 2+N 3 T 3 \ldots . . N x T x)}$

Where $\mathrm{N}$ is the number of seeds germinated every day and $\mathrm{T}$ is the number of days from seedling responding to $\mathrm{N}$ [23].

\subsubsection{Germination Rate Index (GRI)}

A germination rate index (GRI) to evaluate seedling vigour was determined following the procedure described by Bouton et al. [24] and modified by Fowler [25]. GRI was calculated as:

$\mathrm{G} 2 / 2+\mathrm{G} 4 / 4+\mathrm{G} 6 / 6+\mathrm{G} 8 / 8$ 
Where G2, G4, G6 and G8 are germination percentages at 2, 4, 6 and 8 days after sowing respectively.

\subsubsection{Seedling height}

A $30 \mathrm{~cm}$ ruler was used to measure the seedling height after 30 days. A ruler was placed against the plant and the height was measured from the top of the soil up to the apical meristem.

\subsubsection{Final crop stand}

The final crop stand was calculated on the final day of the experiment at 6 weeks.

Final crop stand $=$ surviving $($ standing) seedlings/total planted seeds

\subsubsection{Root length density}

Root length density (RLD) is calculated as the total length of the roots then divided by the volume of the soil sample [26]:

$\mathrm{RLD}=L_{\mathrm{R}} / V$

Where $L_{\mathrm{R}}$ is the length of the living roots $(\mathrm{cm})$ and $V$ is the volume $\left(\mathrm{cm}^{3}\right)$ of the root-permeated soil sample.

2.6 Data analysis

Analysis of variance (ANOVA) was done using GenStat $18^{\text {th }}$ edition and separation of means was done using the least significance difference (LSD) test at a 5\% significant level.

\section{RESULTS}

3.1 Effects of irrigation frequency and soil type on the number of days to $50 \%$ emergence of quinoa seedlings

There was an interaction $(\mathrm{p}<0.05)$ between irrigation frequency and soil type on the number of days to $50 \%$ emergence of quinoa seedlings. Quinoa planted in sandy soils and irrigated after one-day intervals were the fastest to reach $50 \%$ emergence, emerging in an average of 2.67 days [Figure 1], even though there was no statistical difference between quinoa seeds planted in the sand, clay, loam irrigated after 1 day and sand irrigated after 2-day intervals. Quinoa seeds planted in loam soil and irrigated after 3-day intervals and in sandy soils irrigated after 4-day intervals took the longest to reach $50 \%$ emergence. 


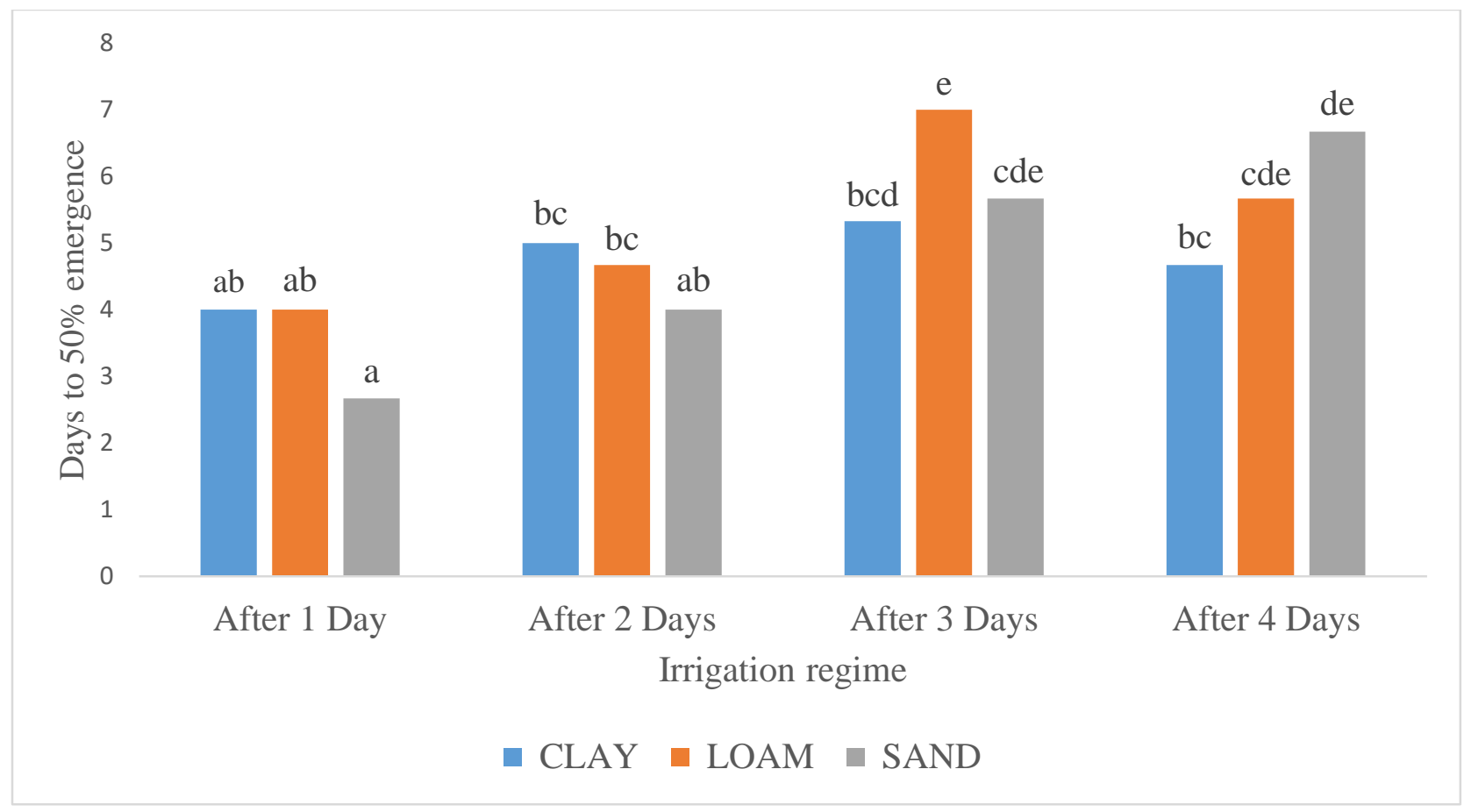

Figure 1 Effect of irrigation frequency and soil type on the number of days taken to reach $50 \%$ emergence of quinoa seedlings.

\subsection{Effects of irrigation frequency and soil type on final germination percentage of quinoa seeds}

There was an interaction $(\mathrm{p}<0.05)$ between irrigation frequency and soil type on the final germination percentage of quinoa seeds. Quinoa seeds planted in sandy soil and irrigated after one-day intervals recorded the highest germination percentage of $96.7 \%$ while seeds planted in clay soil and irrigated after three-day intervals recorded the least germination percentage of $41.7 \%$ [Figure 2]. Seeds planted in loamy soil recorded a similar germination percentage across all four irrigation frequencies averaging $77.5 \%$. 


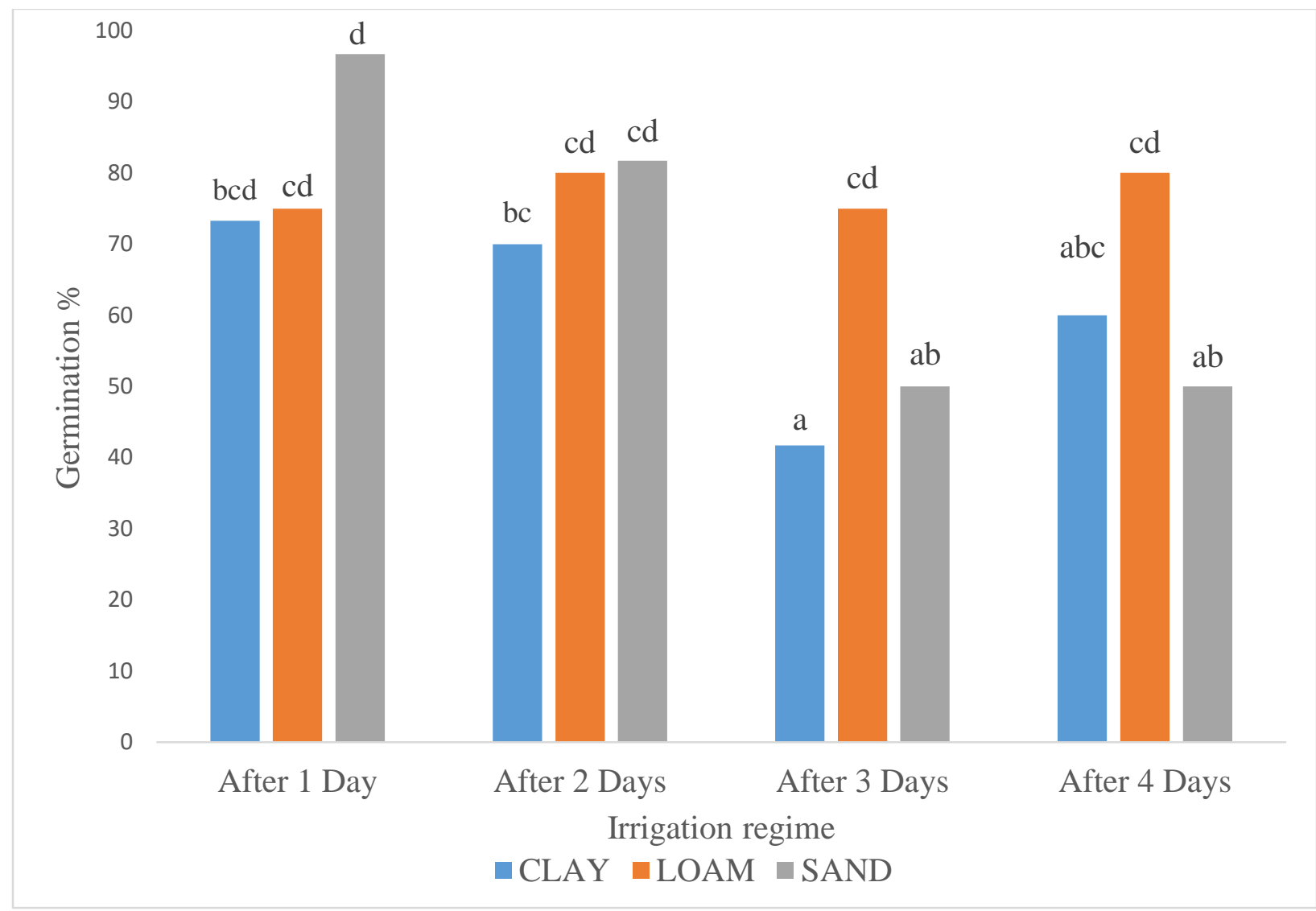

Figure 2 Effect of irrigation frequency and soil type on the final germination percentage of quinoa seeds.

\subsection{Effects of irrigation frequency and soil type on mean germination time of quinoa seeds}

There was no interaction $(\mathrm{p}>0.05)$ between different irrigation frequencies and soil types on the mean germination time of quinoa seeds. There were no significant differences $(p>0.05)$ in the mean germination time of quinoa seeds from different irrigation frequencies. However, the mean germination time of quinoa seeds was influenced by soil type $(\mathrm{p}<0.05)$. The mean germination time was the shortest $(3.25$ days $)$ in quinoa seeds planted in sandy soil. There was no significant difference in the mean number of days between clay soil and loam soils which recorded the longest mean germination time of 4.5 and 4 days respectively [Figure 3]. 


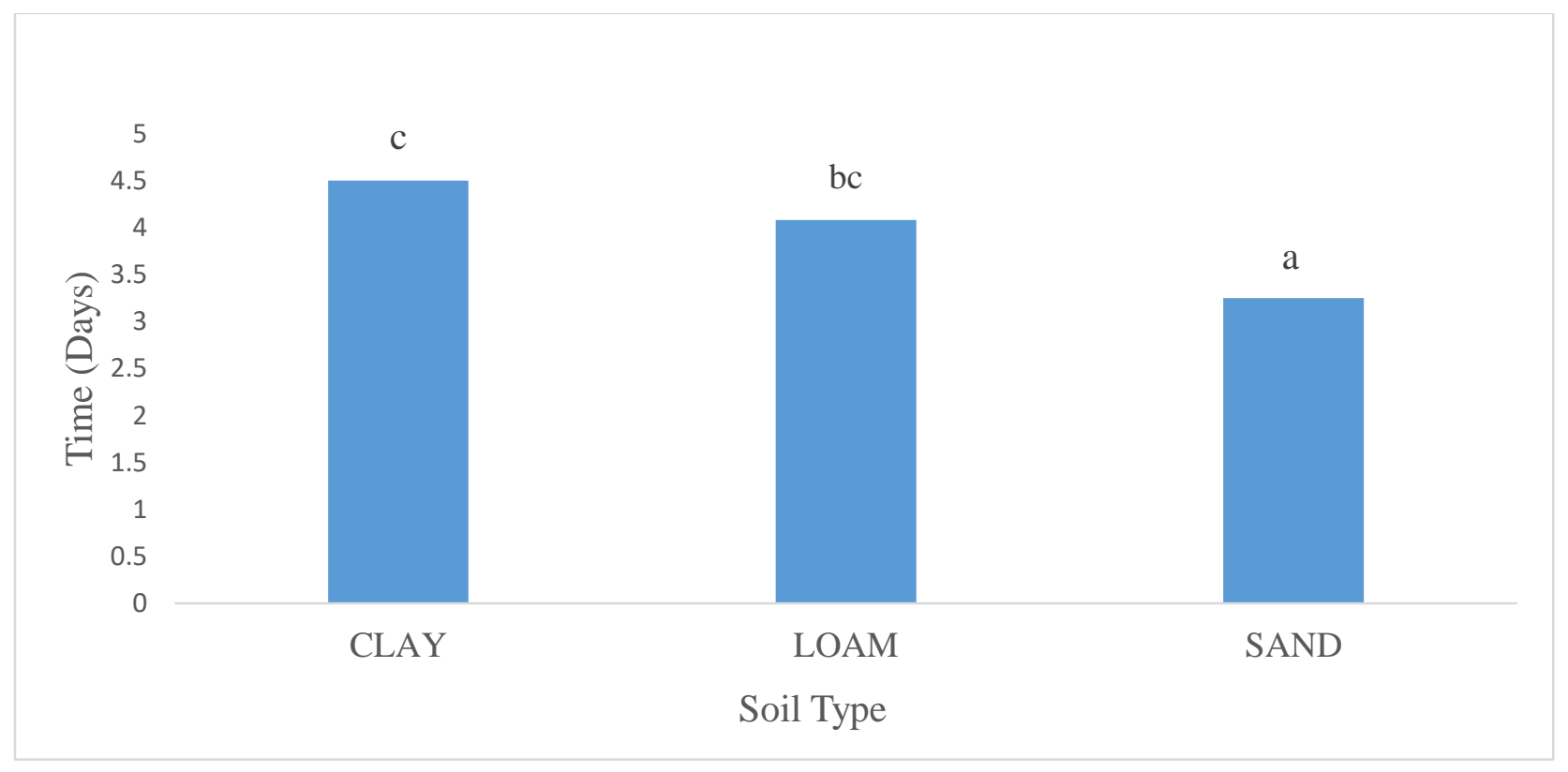

Figure 3 Effects of soil type on mean germination time of quinoa seeds.

\subsection{Effects of irrigation frequency and soil type on germination rate index (GRI) of quinoa seeds}

There was an interaction $(\mathrm{p}<0.05)$ between irrigation frequency and soil type on the germination rate index of quinoa seeds. Quinoa seeds planted in loam soil and irrigated after three days recorded the lowest mean GRI of $29.4 \%$, while seeds planted in sand and irrigated after one day recorded the highest GRI of $70.4 \%$ [Figure 4]. The GRI of quinoa seeds planted in sand soil decreased as the irrigation regime days increased from one day to four days. There was no statistical difference in GRI on clay soil irrigated at the four different frequencies. There was no statistical difference in the GRI of quinoa planted in loam and sand irrigated after 4 days. 


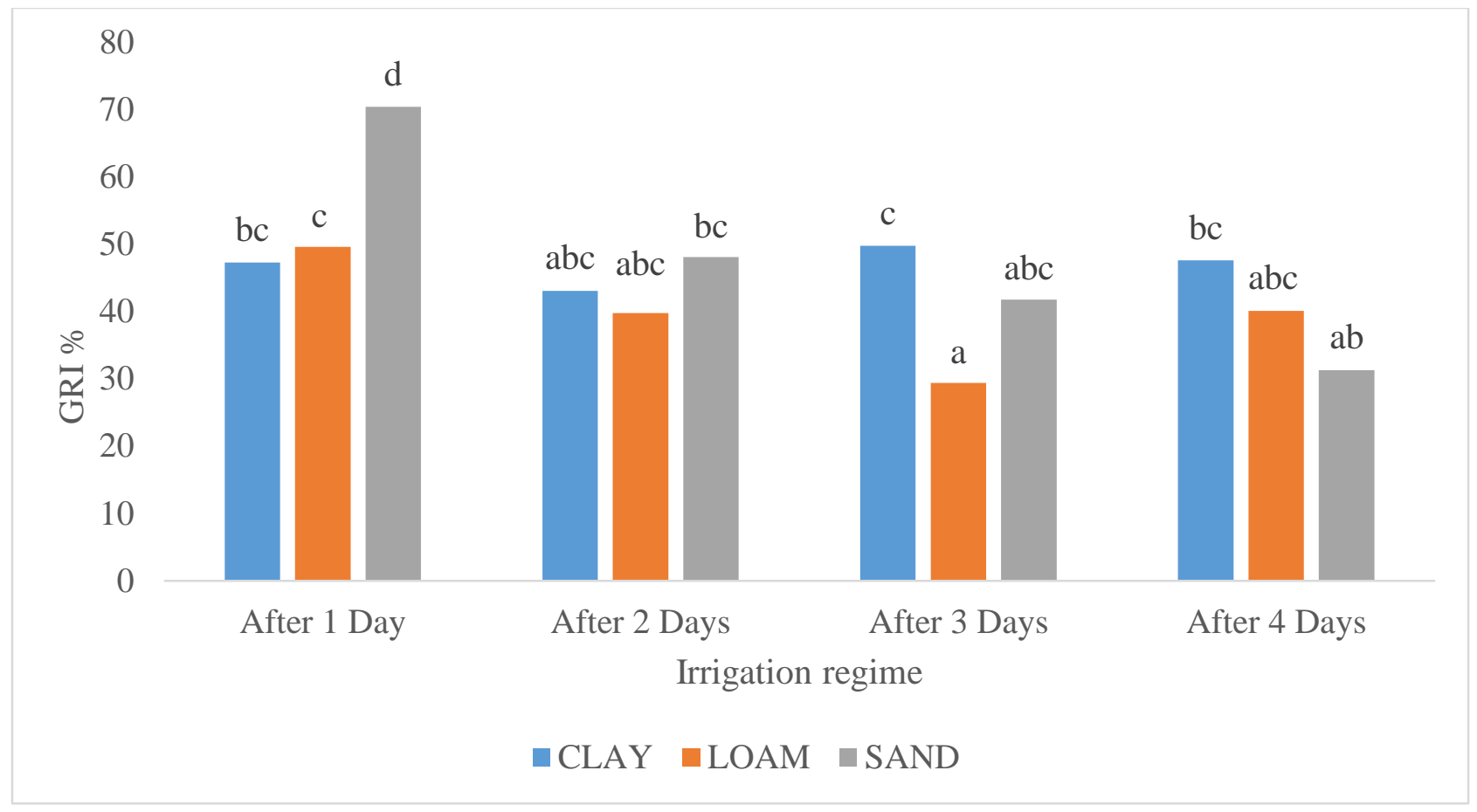

Figure 4 Effect of irrigation frequency and soil type on the germination rate index (GRI) of quinoa seeds.

\subsection{Effects of irrigation frequency and soil type on the coefficient of velocity of germination of quinoa seeds}

There was no interaction ( $p>0.05$ ) between soil type and irrigation regime on the coefficient of velocity of germination of quinoa seeds. There was no significant difference $(p>0.05)$ in the coefficient of velocity of germination of quinoa seeds among different irrigation regimes, neither was there a significant difference $(p>0.05)$ in the coefficient of velocity of germination of quinoa seeds among the different soil types.

\subsection{Effects of irrigation frequency and soil type on the seedling height of quinoa}

There was an interaction $(\mathrm{p}<0.05)$ between irrigation frequency and soil type on the height of quinoa seedlings. Quinoa seedlings in loam soil irrigated on four-day intervals recorded the shortest plants averaging $9.3 \mathrm{~cm}$ although they were not significantly different from quinoa plants planted in sand soil irrigated after 3-day intervals [Figure 5]. There was no statistical difference between the heights of quinoa 
seedlings planted in loamy soil and irrigated after one-day interval and two-day interval. Plant height decreased as the irrigation frequency decreased from one-day interval to four-day interval on all soil types.

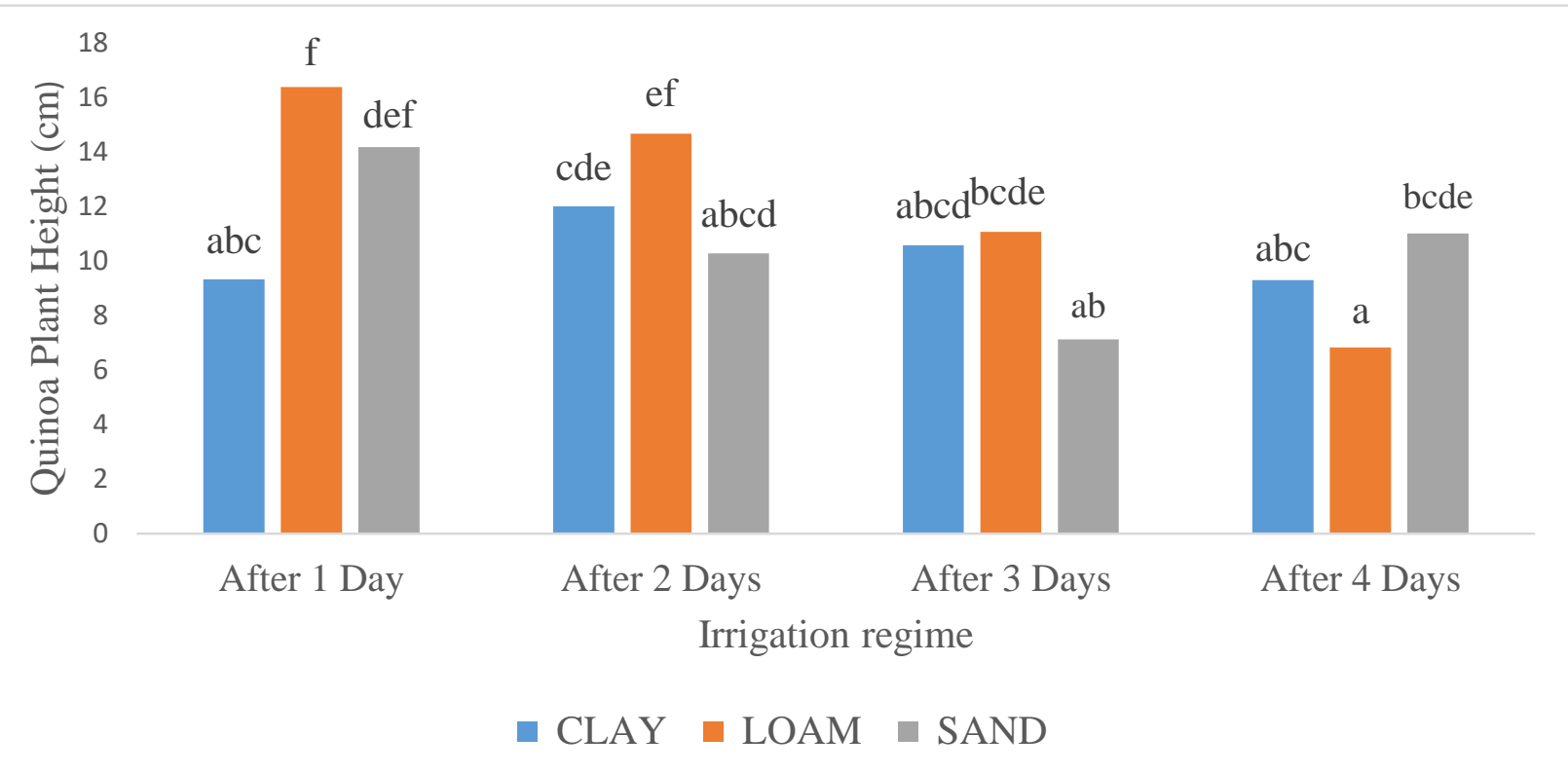

Figure 5 Effect of irrigation frequency and soil type on the seedling height of quinoa seedlings.

\subsection{Effects of irrigation frequency and soil type on the final quinoa crop stand}

There was an interaction $(\mathrm{p}<0.05)$ between soil type and irrigation regime on the final crop stand of quinoa seedlings. The highest quinoa crop stand (85\%) was recorded in sandy soils and irrigated after one-day interval while clay and loam soils under the same irrigation regime recorded lower crop stands. Clay soil irrigated after a 2-day interval recorded the least final crop stand (10\%) [Figure 6]. 


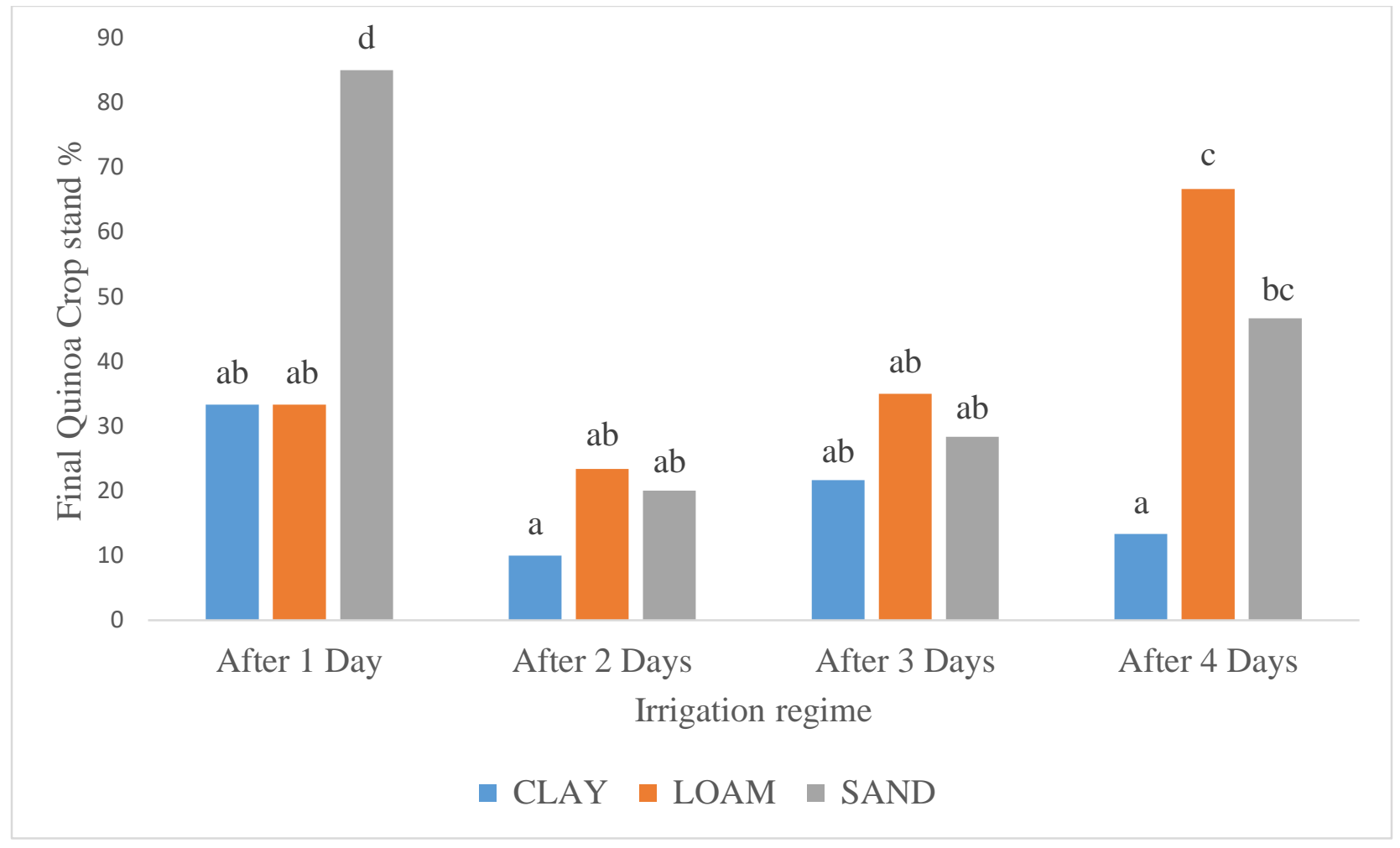

Figure 6 Effects of irrigation frequency and soil type on the final quinoa crop stand at 6 weeks.

\subsection{Effects of irrigation frequency and soil type on root length density of quinoa seedlings}

There was an interaction $(\mathrm{p}<0.05)$ between irrigation frequency and soil type on the root length density of six weeks old quinoa plants. Quinoa planted in loam and irrigated on two-day intervals recorded the lowest root density $\left(3.07 \mathrm{~cm} / \mathrm{cm}^{3}\right)$ while those planted in sandy soil and irrigated on three-day intervals recorded the highest root density of $21.23 \mathrm{~cm} / \mathrm{cm}^{3}$ [Figure 7]. There is an exponential increase in the root density of quinoa seedlings as irrigation frequency was decreased from once after one day to once every three days intervals. 


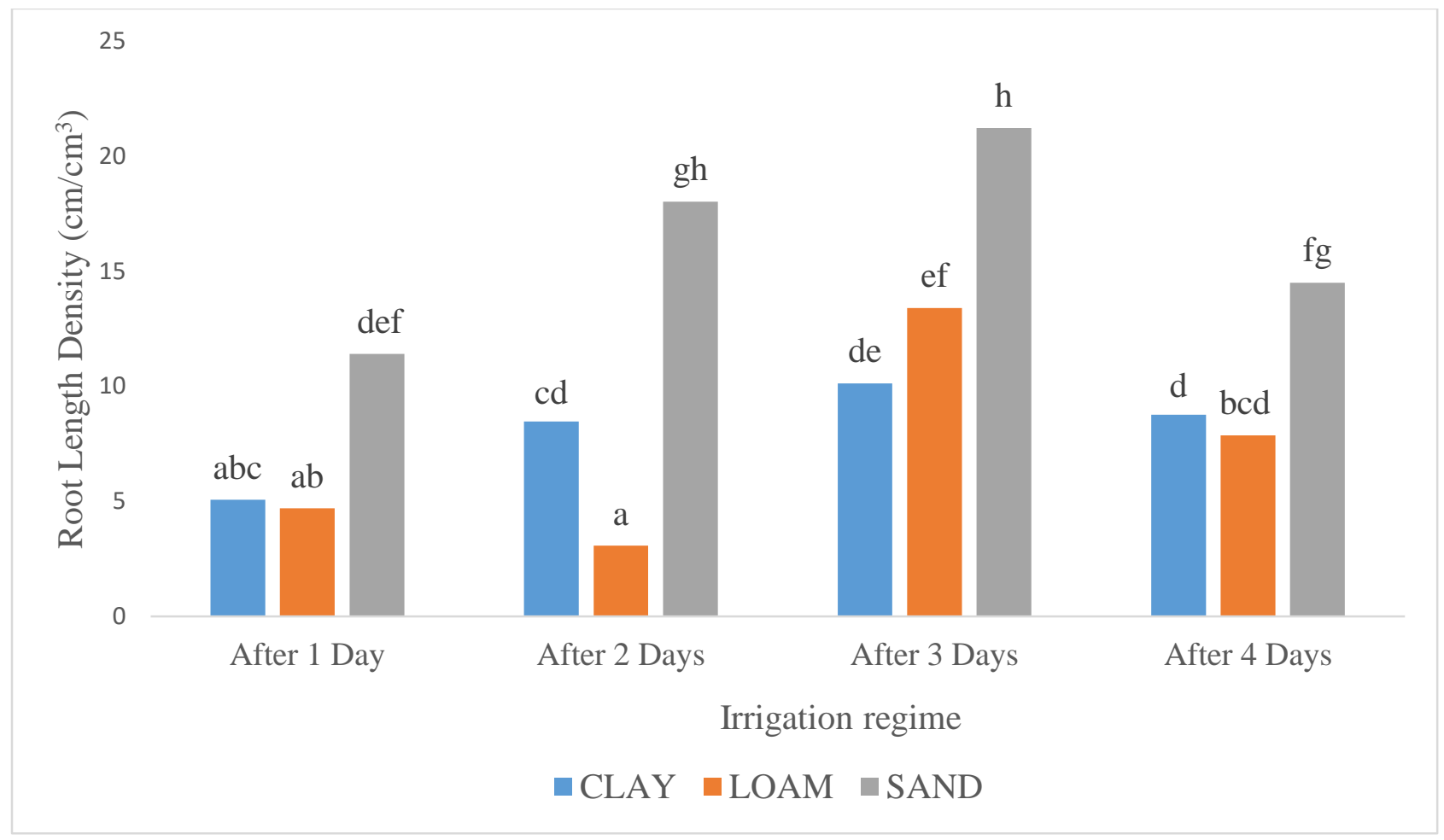

Figure 7 Effect of irrigation frequency and soil type on the root density of six weeks old quinoa seedlings.

\section{DISCUSSION}

\subsection{Effects of irrigation frequency and soil type on the number of days to 50\% emergence, mean germination} time, germination rate index, final germination percentage and final crop stand

The least days to 50\% emergence, shortest mean germination time, the highest final germination percentage, highest germination rate index were in sandy soils with high porosity of 0.96 [Table 1]. A lower porosity translates to poor soil aeration and seed respiration which consequently means lower metabolic energy for seed germination [27] and the reverse is true. The lowest final germination and final crop stand observed in clay soils (bulk density $0.91 \mathrm{~g} / \mathrm{cm}^{3}$ and porosity 0.85 ) [Table 1] could have been due to seed decay emanating from anaerobic conditions [27]. In sandy soils that were frequently irrigated, the high porosity (0.96) ensured that any excess water drained away and that adequate moisture and oxygen which are critical in seed germination and emergence were available. Thus, lack of adequate water supply in seeds resulted in seeds not being able to germinate hence resulted in the decay of some seeds [28]. The high bulk density 
of sand $\left(1.2 \mathrm{~g} / \mathrm{cm}^{3}\right)$ [Table 1] had a positive influence on soil moisture, porosity and seed-to-soil contact. Lapen et al. [29] explained that these characteristics affect seedling emergence. Lafond et al. [30] also stated that seed-to-soil contact is important where high seedling emergence percentages are desired. This is also in agreement with Soureshjani et al. [31] who noted that the best seed-to-soil contact occurred at a bulk density of $1.4 \mathrm{~g} / \mathrm{cm}^{3}$ which gave the best sesame seedling emergence rate. A total porosity that ranges from $0.54-0.96$ is commonly accepted in a growth medium for crop cultivation [32].

\subsection{Effects of irrigation frequency and soil type on quinoa seedling height}

Bulk density determines the water, air and nutrient retention capacity of a given soil while soil $\mathrm{pH}$ determines nutrient availability [33]. The tallest seedlings were observed in loam soil that was irrigated after one-day intervals. Loamy soil had the least bulk density of $0.83 \mathrm{~cm}^{3}$, the seedling height results show the importance of aeration to plant growth. The $\mathrm{pH}$ of the loam soil was 6.8 [Table 1], which is within the optimum range $(6.5-8.5)$ for plant nutrition as reported by Zucconi [34]). Quinoa plants irrigated after four-day intervals recorded the shortest seedlings especially those in sandy soil. This is most probably due to water deficit since sand soil had a high bulk density of $1.2 \mathrm{~cm}^{3}$ and porosity of 0.96 [Table 1 ] and it dried out quickly. Also, the longer irrigation frequency, that is, irrigation after 4 days affected the quinoa height across all soil types. Geerts et al. [35] observed that by decreasing the amount of irrigation water, the value of $\mathrm{pH}$ increased and this has negative effects on plant growth as it makes some essential nutrients unavailable by locking them.

\subsection{Effects of irrigation frequency and soil type on root length density of quinoa seedlings}

The larger root length density was found in the sandy soils that were being irrigated after 3 and 4 days. Under water-stress conditions, plants respond by arresting apical canopy growth and directing attention to

developing an extensive root system that will support the canopy when water is available. Similarly, Joslin et al. [36] found a significant increase in root mass growth under drier conditions in forest roots. Clay and loam soils that were frequently irrigated had the least root densities. These soils due to their low porosity 
values of 0.85 and 0.83 [T respectively probably offered some resistance to root growth, therefore, the root densities under all the four irrigation regimes were very poor as also alluded by Bengough and Mullins [37].

\section{CONCLUSIONS AND RECOMMENDATIONS}

The early establishment of quinoa has been demonstrated to be linked to the type of soil and irrigation frequency. Quinoa seeds that are planted in sandy soils that are frequently irrigated tend to have a higher germination percentage, a faster emergence rate and a better crop stand. Although popular as a droughttolerant crop, quinoa has been shown to be sensitive to water stress, particularly during the early growth, especially in porous and well-drained soils. The quinoa seedling grows faster in sandy and loamy soils that are also frequently irrigated. In less frequently irrigated sandy soils, the young quinoa seedlings developed robust root networks. Results point to the conclusion that in marginal areas that are solely rain-fed, quinoa establishment should be timed to coincide with the wettest period of the rainy season. If under irrigation, then frequent irrigation schedules can be scheduled during the early establishment period.

\subsection{Further research study}

Although conclusive results can be deduced from the research findings on seed germination, emergence and early growth from this nursery experiment, further studies can be done as field experiments and see the effects of irrigation frequency and soil types on more growth parameters, yield and quality of quinoa. Also, different planting depths on the different types of soils and different irrigation types should be investigated to see their impact on the emergence and early growth of quinoa in marginal areas. 


\section{AUTHORS' CONTRIBUTIONS}

PC conceptualized and designed the experiment, analyzed the data and wrote the first draft manuscript. CM conducted the experiment, collected and analyzed the data, and wrote the first draft manuscript. BMN designed the laboratory protocols and analyzed the soil's physical properties. VM, IC, TM edited the first draft manuscript up to the final manuscript, all authors read and approved the final manuscript.

\section{FUNDING}

No funding was received for this research study.

\section{DATA AVAILABILITY}

The raw data used to support the findings of this research study will be available from the corresponding author upon a reasonable request.

\section{CONFLICT OF INTEREST}

The authors declare that there was no conflict of interest.

\section{REFERENCES}

[1] Babatunde, Raphael Olanrewaju, Funke Iyabo Olagunju, Segun Bamidele Fakayode, and Foluke Eunice Sola-Ojo. "Prevalence and determinants of malnutrition among under-five children of farming households in Kwara State, Nigeria." Journal of Agricultural Science 3, no. 3 (2011): 173-181.

[2] F.A.O, (Food and Agricultural Organization of the United Nations). Master Plan for the International Year of Quinoa - a Future Sown Thousands of Years Ago. (2012) Available at: http://www.fao.org/fileadmin/templates/aiq2013/res/en/master_plan.pdf. Accessed 23 February 2020

[3] United Nations, 2012. United Nations Resolution on the Declaration of the IYQ 2013. A Resolution Adopted by General Assembly-A/RES/66/221 in March 2012. Available at: http://www.unngls.org/IMG/pdf/IYQ.pdf Accessed 06 March 2020 
[4] Jacobsen, S-E., and O. Stølen. "Quinoa-morphology, phenology and prospects for its production as a new crop in Europe." European Journal of Agronomy 2, no. 1 (1993): 19-29.

[5] Rojas, Wilfredo, Patricio Barriga, and Heriberte Figueroa. "Multivariate analysis of the genetic diversity of Bolivian quinua germplasm." Plant Genetic Resources Newsletter 122 (2000): 16-23.

[6] Garcia, Magalí, Dirk Raes, and Sven-Erik Jacobsen. "Evapotranspiration analysis and irrigation requirements of quinoa (Chenopodium quinoa) in the Bolivian highlands." Agricultural Water Management 60, no. 2 (2003): 119-134.

[7] Jacobsen, S-E., A. Mujica, and C. R. Jensen. "The resistance of quinoa (Chenopodium quinoa Willd.) to adverse abiotic factors." Food Reviews International 19, no. 1-2 (2003): 99-109

[8] Hinojosa, Leonardo, Juan A. González, Felipe H. Barrios-Masias, Francisco Fuentes, and Kevin M. Murphy. "Quinoa abiotic stress responses: A review." Plants 7, no. 4 (2018): 106.

[9] Aguilar, Pablo Cesar, and Sven-Erik Jacobsen. "Cultivation of quinoa on the Peruvian Altiplano." Food Reviews International 19, no. 1-2 (2003): 31-41.

[10] Fuentes, F., and A. Bhargava. "Morphological analysis of quinoa germplasm grown under lowland desert conditions." Journal of Agronomy and Crop Science 197, no. 2 (2011): 124-134.

[11] González, J. A., M. Bruno, M. Valoy, and F. E. Prado. "Genotypic variation of gas exchange parameters and leaf stable carbon and nitrogen isotopes in ten quinoa cultivars grown under drought." Journal of Agronomy and Crop Science 197, no. 2 (2011): 81-93.

[12] Barrientos, E., F. Carevic, and J. Delatorre. "The sustainability of the southern highlands of Bolivia and its relationship with the expansion of quinoa growing areas." Idesia 35, no. 2 (2017): 7-15.

[13] Sun, Y., F. Liu, M. Bendevis, S. Shabala, and S-E. Jacobsen. "Sensitivity of two quinoa (ChenopodiumquinoaWilld.) varieties to progressive drought stress." Journal of Agronomy and Crop Science 200, no. 1 (2014): 12-23. 
[14] Walters, Hannah, Lynne Carpenter-Boggs, Kefaylew Desta, Lin Yan, Janet Matanguihan, and Kevin Murphy. "Effect of irrigation, intercrop, and cultivar on agronomic and nutritional characteristics of quinoa." Agroecology and Sustainable Food Systems 40, no. 8 (2016): 783-803.

[15] Oyoo, M. E., S. M. Githiri, and P. O. Ayiecho. "Performance of some quinoa (Chenopodium quinoa Willd.) genotypes in Kenya." South African Journal of Plant and Soil 27, no. 2 (2010): 187-190.

[16] Gardner, Morgan, Moses FA Maliro, Jessica R. Goldberger, and Kevin M. Murphy. "Assessing the potential adoption of quinoa for human consumption in central Malawi." Frontiers in Sustainable Food Systems 3 (2019): 52.

[17] Muziri, Tavagwisa, Paul Chaibva, Anyway Chofamba, Tendai Madanzi, Pepukai Mangeru, Nhamo Mudada, Shephard Manhokwe et al. "Using principal component analysis to explore consumers' perception toward quinoa health and nutritional claims in Gweru, Zimbabwe." Food Science \& Nutrition 9, no. 2 (2021): 1025-1033.

[18] Jayne, Thomas S., David Mather, and Elliot W. Mghenyi. Smallholder farming under increasingly difficult circumstances: Policy and public investment priorities for Africa. No. 1096-2016-88426. 2006.

[19] Blake, G. R. "Bulk density." Methods of Soil Analysis: Part 1 Physical and Mineralogical Properties, Including Statistics of Measurement and Sampling 9 (1965): 374-390.

[20] Hao, X., B. C. Ball, J. L. B. Culley, M. R. Carter, and G. W. Parkin. "Soil density and porosity." Soil sampling and methods of analysis (2008): 743-759.

[21] Rayment, George E., and David J. Lyons. Soil chemical methods: Australasia. Vol. 3. CSIRO publishing, 2011.

[22] Ellis, R. H., and E. H. Roberts. "The quantification of ageing and survival in orthodox seeds." Seed Science and Technology (Netherlands) (1981). 
[23] Pollock, Bruce M., and Eric E. Roos. "Seed and seedling vigor." Seed Biology, I. Importance, development and germination (1972): 314-387.

[24] Bouton, J. H., A. E. Dudeck, and R. L. Smith. "Germination in Freshly Harvested Seed of Centipedegrass 1." Agronomy Journal 68, no. 6 (1976): 991-992.

[25] Fowler, J. L. "Interaction of salinity and temperature on the germination of crambe." Agronomy Journal 83, no. 1 (1991): 169-172.

[26] Smit, Albert L., A. Glyn Bengough, Christof Engels, Meine van Noordwijk, Sylvain Pellerin, and Siebe C. van de Geijn, eds. Root methods: a handbook. Springer Science \& Business Media, 2013.

[27] Baiyeri, K. P., and B. N. Mbah. "Effects of soilless and soil-based nursery media on seedling emergence, growth and response to water stress of African breadfruit (Treculia africana Decne)." African Journal of Biotechnology 5, no. 15 (2006).

[28] Bewley, J. Derek, and Michael Black. "Cellular events during germination and seedling growth." In Seeds, pp. 147-197. Springer, Boston, MA, 1994.

[29] Lapen, D. R., G. C. Topp, E. G. Gregorich, H. N. Hayhoe, and W. E. Curnoe. "Divisive field-scale associations between corn yields, management, and soil information." Soil and Tillage Research 58, no. 34 (2001): 193-206.

[30] Lafond, G. P苚, and D. A. Derksen. "Row spacing and seeding rate effects in wheat and barley under a conventional fallow management system." Canadian journal of plant science 76, no. 4 (1996): 791-793.

[31] Soureshjani, Hedayatollah Karimzadeh, Mahmoud Bahador, MahmoudReza Tadayon, and Ayoub Ghorbani Dehkordi. "Modelling seed germination and seedling emergence of flax and sesame as affected by temperature, soil bulk density, and sowing depth." Industrial Crops and Products 141 (2019): 111770.

[32] Gessert, George. "Measuring a medium's air space and water holding capacity." Ornamentals Northwest 1, no. 8 (1976): 11-12. 
[33] Fageria, N. K., G. D. Carvalho, A. B. Santos, E. P. B. Ferreira, and A. M. Knupp. "Chemistry of lowland rice soils and nutrient availability." Communications in Soil Science and Plant Analysis 42, no. 16 (2011): 1913-1933.

[34] Zucconi, F. de. "Compost specifications for the production and characterization of compost from municipal solid waste." Compost: production, quality and use (1987): 30-50.

[35] Geerts, Sam, Dirk Raes, Magali Garcia, Octavio Condori, Judith Mamani, Roberto Miranda, Jorge Cusicanqui, Cristal Taboada, Edwin Yucra, and Jean Vacher. "Could deficit irrigation be a sustainable practice for quinoa (Chenopodium quinoa Willd.) in the Southern Bolivian Altiplano?." Agricultural Water Management 95, no. 8 (2008): 909-917.

[36] Joslin, J. D馬, M. H茾 Wolfe, and P. J. Hanson. "Effects of altered water regimes on forest root systems." The New phytologist 147, no. 1 (2000): 117-129.

[37] Bengough, Anthony G., and Chris E. Mullins. "Mechanical impedance to root growth: a review of experimental techniques and root growth responses." Journal of soil science 41, no. 3 (1990): 341-358. 